\title{
Triple Bottom Line: Exploratory Data Analysis of Lodging Real Estate Investment Trusts
}

\author{
Paper Hartman \\ California State University Dominguez Hills \\ $\underline{\text { lhartman2@toromail.csudh.edu }}$
}

\begin{abstract}
Popular frameworks for firm efficiency were developed $40+$ years ago by educated, Western businessmen. The world is different now and needs to be analyzed through modern lenses to address complex and evolving business challenges. Students learn how firms can become profitable, however, modern curriculum still does not address why. Corporate Social Responsibility (CSR) created space to consider People, Planet, and Profit in topline decision-making, however CSR has become an echo chamber. This research aims to provide a purpose for profit by asking what popular focuses are in an industry, how they differ among firms, and how this research might be used for the benefit of all stakeholders. Firms can use this analysis for decision-making to innovate allocation of resources, educational deployment, and investment in infrastructure to better serve the purpose of profit; external stakeholders can use this analysis to explore industry-wide policy gaps and create tailored solutions for societal needs.
\end{abstract}

\section{Introduction}

Corporate responsibility is highly debated and is typically practiced from one of three main theoretical perspectives; stakeholder, business ethics, or shareholder value [1]. Stakeholder theory serves all stakeholders in a firm's value chain, not just shareholders. Stakeholders include suppliers, employees, customers, investors, and communities who are impacted by a firm's decisions. A firm acting under stakeholder theory analyzes its decision-making in terms of a decision's effect on any number of stakeholders [2].

A business ethics framework focuses on decisions that are initiated after legal obligations are met. The problem with outright legislating social responsibility is threefold; primarily, ethics itself is approached from at least four different frameworks with conflicting moral guidance, most commonly practiced as either utilitarianism (the greatest good for the greatest number of people) or deontology (if the intent of a decision is good will, the consequences do not matter) [3]. Differences in approach to ethics makes ethical business decisions difficult to quantify or qualify, and while a deontological perspective of business ethics may provide moral imperatives as a guide to decision-making, a business in and of itself lacks the "ability to reason" and decisions often default to the moral code of the individual tasked with a decision, which then creates an array of gold standards instead of a singular north star [4]. Similarly and secondarily, social remedies are complex, multifaceted, and often work to address conflicting values, thus a utilitarian perspective is difficult to execute unless extensive qualitative data are analyzed for themes that apply to the majority of stakeholders and their needs. Though a business may indeed lack the ability to reason, it is most certainly not bereft of data from which reasoning can be derived.

However, addressing what is best for most still ignores the needs of some. In a world where news, advertisements, and even search queries are tailored to the end-user's preferences through complex analysis of qualitative and quantitative data (algorithms) [5], there is ample opportunity to tailor solutions for specific issues based on the same type of machine learning.

The third problem with legislating business ethics comes from the struggle between standardization and innovation which is currently debated in the scientific management field [6]. Some analysts argue that the two are mutually exclusive, while others support the idea that standardization promotes innovation. Regardless, research on the subject is inconsistent, but it is obvious that there is no one-size-fits-all approach to business ethics theory to address CSR.

Shareholder value theory, otherwise known as the Friedman Doctrine, is the most widely-practiced and 
focuses on maximizing profit for the benefit of shareholders while disavowing any social responsibility. In plain terms, businesses exist to make money for their investors and owe nothing to society [7]. This perspective is criticized by contemporaries, but often on semantics that wax over what the legal definition of "agent" is and how agency theory does not subrogate the definition of ownership [8].

These three theoretical perspectives bring their own truths and accompanying bodies of research to the table, but business as a science is a relatively new field compared to areas like biology, anthropology, and medicine. There is still space to innovate and unite perspectives for posterity's sake; what the community lacks, however, is time.

Moore's Law states that the number of transistors on a microchip doubles every two years while the cost of computers decreases by half in as much time, and while the research presented in this manuscript is not about hardware, Moore's Law illustrates that it is only a matter of time before technology becomes infinitely capable and free. With technological innovation disrupting the fabric of society and distribution of labor, disciplines like business science must develop more anticipatory, flexible models using technology that better-serve every stakeholder in its value chain to keep up with stakeholder demands, internally and externally.

The purpose of profit is to innovate; competition is responsible for advancements in technology, medicine, communication, and transportation but it is also responsible for an increasing wealth-gap domestically, and subjugation of new efficiency frontiers abroad. There is nothing inherently bad about a firm amassing wealth for the purpose of innovation or even for simple pleasure, but if even a single constituent in a value chain does not have their basic needs met as part of their resource exchange with a firm, a firm cannot reasonably consider itself to be profitable. This approach implies that not only do top firms need to improve their own shareholder value accountability and sincerity, but should also conduct stricter due diligence in fostering responsible business with others upstream. Through this endeavor, profit cannot be earned due to an imbalance of power between firms and their value chain partners.

To apply this assertion to a real-world business model, an extensive set of surveys would need to be conducted and analyzed for what those basic needs are, as well as what the costs involved are, and to-where firm resources should be deployed. Without the time or resources to attain a rich primary data set for this exercise, the most viable option is to perform a document analysis of existing qualitative data to see what introspection can be gleaned. This study performs a document analysis of qualitative firm data to evaluate where current CSR policies are focused as a first step towards aligning initiatives with needs.

Some of the questions this document analysis sets out to answer are 1) how do CSR approaches differ among firms in an industry, 2) what are the most popular focuses of CSR in an industry, and 3) how can these methods be used for the benefit of internal and external stakeholders?

In order to collect a focused body of documents, the study needs to be limited to one well-defined industry. The devastating effects of Covid-19 on the hotel industry makes it a compelling case to find a deeper understanding of how CSR is managed in hotels. In researching the organizational structures of hotel management, a segment of hotel ownership groups called Lodging Real Estate Investment Trusts (REITs), which are publicly-traded and range in differentiation and diversification strategies, stands out. Additionally, the REIT segment of hospitality ownership groups is a splendid microcosm of both standardization and innovation working hand-in-hand, with a variety of business models to evaluate. Some firms focus on select-service hotels while others on luxury resorts, and a single portfolio can contain both highly standardized processes from top chain brands like Hilton and Marriott, and independent boutique assets with more room for proprietary innovation. Most importantly, their initiatives and firm performance are available to view publicly due to their profile with the Securities Exchange Commission.

In the Big Data era, there are virtually limitless qualitative data to help companies understand how effective their CSR strategies are in capturing their true economic and shared value; that is, initiatives should not serve to be a marketing tool to attract more customers, or a tax-deductible line item, but rather to actually make a difference in their respective areas by integrating qualitative data, ethical business, and stakeholder theories. In this document analysis, the REIT industry is evaluated for its Triple Bottom Line (TBL) initiatives in a qualitative format to see if any insights can be gained about the information firms share publicly, and how industries can use their abundance of qualitative data to create meaningful shared value that fulfills a firm's and stakeholder's respective prosperities.

Data are only as good as the reasons behind collection, so in order to justify the energy and resources required to collect and store qualitative data on an enterprise level, it is critical for firms to 
maximize their investment, especially if that investment provides opportunities to increase the sincerity and effectiveness of their TBL strategies.

\section{Theoretical background}

In the early 1900's, Frederick Taylor's Scientific Management theory gave firms insights on how to quantitatively manage their production and growth [9]. However, even Taylor opens his paper by stating that the "object of management should be to secure the maximum prosperity for the employer, coupled with the maximum prosperity for each employee" [10]. The evolution of management theory has taken many directions, with both qualitative and quantitative research to support studies on organizational development and resource management to maximize firm efficiency, but in the current age of Big Data and a race for knowledge-based excellence among the world's most competitive nations, three primary focuses stand out to organize sustainability as a strategy to address maximum prosperity not only for firms, but for employees and other stakeholders as well.

People, Planet, and Profit constitute the "3Ps" of the Triple Bottom Line (TBL) coined by John Elkington in 1994 [11]. Elkington set out to enact systemic change in the transformation of capitalism on the brink of the technological era in which we presently find ourselves. Well in advance of Elkington's introduction of TBL, corporations began exploring preliminary CSR initiatives to address worker well-being and productivity in newly industrialized Western societies. In as early as 1953, economist Howard Bowen published a book titled "Social Responsibilities of the Businessman" to outline why it is imperative for corporate decision makers to not only comply with laws and regulations, but to consider an ethical approach to decisions that affect society at large. Bowen himself implores businesspeople to act "as servants of society" [12].

By the mid-1980's, acclaimed business scholars such as Michael E. Porter were writing about firm efficiency in terms of competitive advantage by focusing on economic value creation through cost-leadership and differentiation strategies. While there is nothing inherently wrong with firm efficiency and value creation, the theory largely bypasses any discussion of social responsibility on behalf of the firm's pursuit of its own prosperity. This is aligned with Friedman's shareholder value and agency theory. To this day, Porter's theoretical framework of value creation is emphasized in undergrad lecture halls of the world's best business schools, with only a chapter or two devoted to CSR towards the end of each course.

However, the past two decades have brought an exponential increase in globalization due to technological advancements in telecommunications and transportation, and the discussion of both CSR and TBL has resurfaced as firms seek internationalization methods to continue expanding their efficiency frontiers. In 2011, Porter introduced a theoretical framework to augment his previous research and writings with a discussion on Creating Shared Value (CSV), by which a firm can increase its value creation through optimization and capitalization of its TBL [13]. The concept of CSV is not without fault or criticism; progressive business scholars have rejected the insincere nature of Porter's CSV framework on the basis that these constructs only serve as another means of measure for firm performance to address problems with capitalism, rather than as a means to address problems of social inequities. The opposing views struggle over the intrinsic nature of CSV; is it a framework of the heart or of the almighty dollar? In 2018, Elkington wrote in the Harvard Business Review that he believes it is time to rethink and "recall" his initial proposal because TBL has been reduced to line items on a balance sheet. However, in realistic terms, TBL theory balances "duty of care" with corporate governance, both to meet regulations and to exceed society's expectations and needs [14].

A ubiquitous industry such as hotels has far reach and relatability for both employees and consumers. Out of $157 \mathrm{M}$ jobs in the United States between 2018 and 2019 [15], roughly $2.3 \mathrm{M}$ of those jobs were in hotels, or $1.47 \%$ of all US jobs [16]. With over $5 \mathrm{M}$ hotel keys in the US [17] and a nationwide occupancy rate of $66.1 \%$ [18], roughly $1.2 \mathrm{~B}$ people either slept in a hotel bed or worked in a hotel in 2019 in the US alone. These understated numbers do not account for length of hotel stay or employee turnover, which further supports the use of hotel data for this document analysis based on its relatability alone.

\section{Data and methods}

The targeted sample set began with a comprehensive list of Lodging REITs in North America, but needed some additional parameters to pare the industry down further so that the firms were relatively aligned in terms of resources and size. A record of each firm's market capitalization from fiscal year 2019 (prior to the black swan event in 2020) enabled the study to identify a range of revenues that would be suitable to define the sample industry. 
Table 1. Lodging REITs in North America

\begin{tabular}{|l|l|l|}
\hline Lodging REIT in USA & $\mathbf{2 0 1 9}$ Revenue (in M) & Stock Symbol \\
\hline Condor Hospitality Trust & $\$ 61$ & (CDOR) \\
\hline Southerly Hotels & $\$ 185$ & (SOHO) \\
\hline CorePoint Lodging & $\$ 235$ & (CPLG) \\
\hline Pebblebrook Hotel Trust & $\$ 350$ & (PEB) \\
\hline Sunstone Hotel Investors & $\$ 358$ & (SHO) \\
\hline MGM Growth Properties & $\$ 363$ & (MGP) \\
\hline Chesapeak Lodging Trust & $\$ 403$ & (CHSP) \\
\hline Ryman Hospitality Properties & $\$ 446$ & (RHP) \\
\hline Summit Hotel Properties & $\$ 478$ & (INN) \\
\hline Braemar Hotels \& Resorts & $\$ 488$ & (BHR) \\
\hline Hersha Hospitality Trust & $\$ 529$ & (HT) \\
\hline Park Hotels \& Resorts & $\$ 659$ & (PK) \\
\hline Chatham Lodging Trust & $\$ 674$ & (CLDT) \\
\hline DiamondRock Hospitality & $\$ 863$ & (DRH) \\
\hline Xenia Hotels & $\$ 1,149$ & (XHR) \\
\hline Apple Hospitality & $\$ 1,267$ & (APLE) \\
\hline RLJ Lodging Trust & $\$ 1,300$ & (RLJ) \\
\hline Service Properties Trust & $\$ 1,400$ & (SVC) \\
\hline Ashford Hospitality Trust & $\$ 1,503$ & $(\mathrm{AHT})$ \\
\hline Host Hotels \& Resorts & $\$ 2,500$ & (HST) \\
\hline
\end{tabular}

\subsection{Data collection}

The data used in this document analysis were from firms with a range of market capitalization between $\$ 300 \mathrm{M}$ and $\$ 750 \mathrm{M}$, with one outlier on either end. Each firm's TBL documentation was scraped from the internet and was typically labeled as ESG (Environmental, Social, and Governance) or CSR (Corporate Social Responsibility). From each firm's publicly available documents, both policies and reports provided a rich set of qualitative data, mainly in the form of PDFs from the firms' websites. Documents were tracked with their source links on a spreadsheet, along with the number of properties in each firm's portfolio, their headquarter location, and their CSR score from CSRhub.com [19].

The number of females on their boards, and whether or not any members could be considered minorities, was also initially logged to see if there were any conclusions to be drawn from their presence in a firm's oversight, however the time constraints of the exercise did not allow for further investigation. Likewise, the size of the portfolio and headquarter location could have an impact on the types of programs in place in terms of enterprise resources available due to economy of scale, or local regulatory agencies and standards by county and state.
Table 2. Lodging REIT data collection grid Lodging REIT in USA \# of Hotels $F$ M Doc\# Rating

\begin{tabular}{l|l|l|l|l|l}
\hline Chatham Lodging Trust & 39 & 1 & N & 5 & 12 \\
\hline CorePoint Lodging & 203 & 2 & N & 1 & 13 \\
\hline DiamondRock Hospitality & 31 & 3 & N & 6 & 62 \\
\hline Hersha Hospitality Trust & 37 & 2 & Y & 1 & 56 \\
\hline MGM Growth Properties & 15 & 1 & N & 3 & 52 \\
\hline Park Hotels \& Resorts & 59 & 5 & N & 5 & 12 \\
\hline Pebblebrook Hotel Trust & 56 & 2 & N & 1 & 37 \\
\hline Ryman Hospitality Properties & 7 & 3 & N & 4 & 21 \\
\hline Summit Hotel Properties & 72 & 0 & N & 5 & 32 \\
\hline Sunstone Hotel Investors & 17 & 3 & N & 7 & 31
\end{tabular}

[20] - [32]

\subsection{Data sample summary}

Each firm presented a unique quantity and style of documents available, but to preserve a breadth of firm differences, all available documents were kept in the data sample instead of going toe-to-toe on the type or the number of documents. It was important to consider that the authors' voices would play a role in the analysis; a greater number of documents were anticipated to produce better outcomes in terms of clarity and comparison.

For instance, Chatham Lodging had five sub-categorical documents available, while Hersha Hospitality Trust had a single annual report. Since there is no standard for how a firm presented their TBL initiatives, all documents were included to allow for as much data as possible for the best output, while leaving room to allow for individual writing style to be captured.

Once the documents were compiled, they were imported to Nvivo, classified as either a policy or report, and tracked for three attributes: CSR type (General, People, Planet, and Profit), organization name, and year published. It was clear that Hersha and Pebblebrook did not contribute any policy documents to the research, which immediately presented a future opportunity to equalize the body of documents being analyzed. Additionally, there were no reports specifically addressing how a firm's CSR initiatives performed for "people"; most firm reports addressed their programs as a whole, which may be an opportunity for decision makers to evaluate what kind of information they are reporting, and how.

\subsection{Data coding}

Auto-code is a powerful Nvivo feature that automatically identifies nodes (common keywords or 
themes). In this document analysis, auto-code resulted in a large number of frustratingly useless nodes, but instead of undoing the query, the tool was used for another purpose. Among the many nodes found were words like "the" and "business", so a word frequency analysis was performed to add all of these redundant words to a "stop words" list to prevent their bearing on the analysis. After detecting "stop words", the auto-code action was deleted and the documents were manually coded for three main nodes: People, Planet, and Profit. This task started out quite tedious for the General documents that recapped a firm's entire TBL program (reports), but went relatively quickly for the documents that were dedicated to specific arms of TBL (policies). The stop words list worked as expected because after performing a word frequency analysis for each of the three parent nodes, additional words and phrases were identified as children, or new themes that presented themselves as sub related to a parent node.

The nomenclature for coding in Nvivo represents a hierarchical structure reminiscent of a family tree. Figure 1 below from Oracle's Documentation Help Center on designing custom encoders for abstract message structure [33] illustrates how Nvivo creates relationships between data themes, with roots being the aggregate of all sub themes, and leaves having no posterity. Parent nodes give way to sub classifications called children, which can either have siblings (horizontally related) or no progeny (leaves).

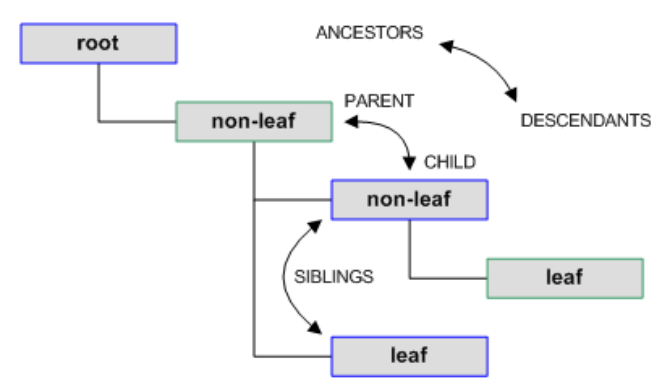

Figure 1. Encoder node relationships [33]

One of the ways to visualize the child nodes of Planet was by performing a word frequency analysis by parent node and exporting a word cloud of children for each.

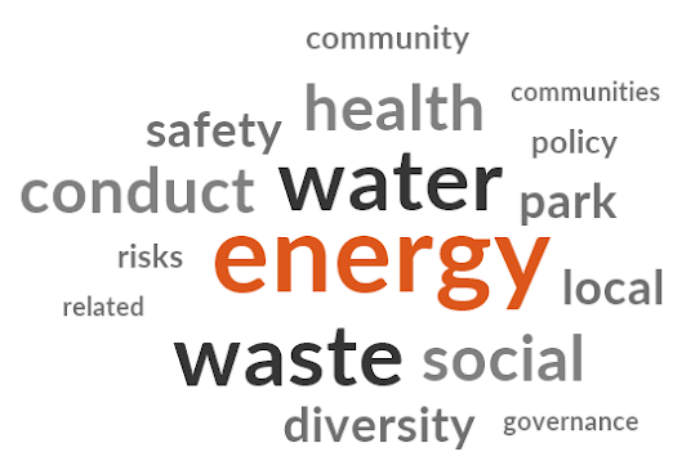

Figure 2. Word frequency analysis by top 16 child nodes for Planet parent node

The result of this Planet node analysis was a small cloud of just 16 words as seen above in Figure 2, so the analysis was run again to capture additional children. The larger cloud in Figure 3 below displayed a wider range of terms used in the industry's Planet initiative documentation; terms like "materials" and "ethics" appear alongside "design" and "standardized" which gave more insights into how the Lodging REIT industry approaches Planet initiatives, from an ethical and standardized framework as expressed in the introduction. A further analysis of the Ethics children might divulge which ethical perspective is most popular among these firms, though an aggregate analysis would not necessarily be appropriate for a firm seeking to improve its own processes and innovate for more sincere purpose and market differentiation. Instead, this presents an opportunity for a firm to evaluate its own contribution to the aggregate on an individual basis.

In the following Figure 3, it was also interesting to note that there are clearly not 100 words captured in the 100 word parameter set. Some of the words captured could potentially be filtered out due to redundancy. Notably, aside from stop words and redundant words, there are less than 30 unique words used in all 38 documents as they pertain to the Planet. This is important because it allows analysts inside and outside the industry to see what topics are being presented as the most important areas, as well as the ability to identify areas that are not being addressed. 


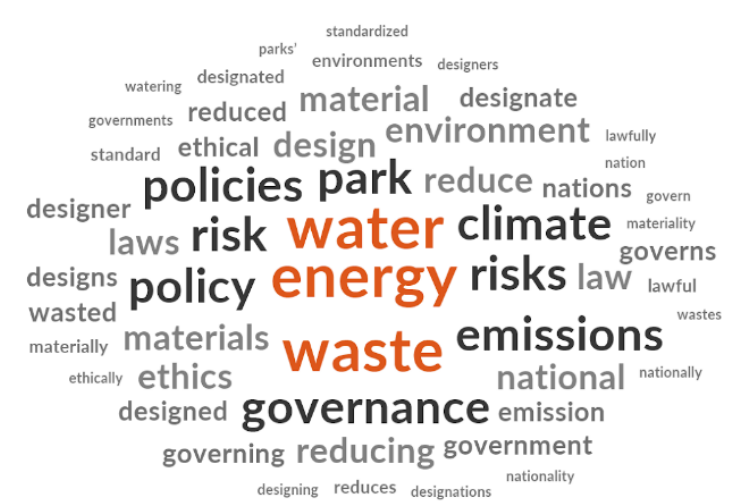

Figure 3. Word frequency analysis by top 100 child nodes for Planet parent node

\section{Analysis}

6 hours were logged using different analyses within Nvivo to derive something meaningful from the data that had been previously researched, collected, classified, and coded over 14 hours. The most clear result was output from a Crosstab Query of People children nodes, which delivered a table that showed how many times a child appeared in a document, organized by the firm name (attribute).

Table 3. TBL crosstab of People child node frequency in each firm, sample

\begin{tabular}{|l|r|r|r|}
\hline Report & Chatham & Diamondrock & Hersha \\
\hline People & 4 & 2 & 1 \\
\hline Community & 5 & 3 & 1 \\
\hline Diversity & 3 & 4 & 1 \\
\hline Donation & 1 & 1 & 1 \\
\hline Health & 3 & 2 & 1 \\
\hline
\end{tabular}

This query was exported to Excel to derive some additional meaning, however this presented a challenge stemming from the decision to keep all firm documents in the analysis, regardless of quantity, length, or style. Despite the number of documents each firm contributed, a simple word count would be unreliable since the documents varied in total length and quantity. However, Table 4 below visualizes each child node as a percentage of the document set, or a percentage of the total of other child node counts for each firm. The pivot table shows four Planet nodes between Hersha and Park as a percentage in relation to one another. This information helps answer "how do TBL approaches differ among firms in an industry?" The table clearly shows that while Hersha spent an equal amount of time discussing climate, emissions, energy, and ethics in their annual report, Park focused heavily on energy, followed by ethics.

\section{Table 4. Pivot table of Planet child nodes to compare ratios of each node within firm documents}

\begin{tabular}{|lrr|}
\hline Row Labels & Sum of Hersha & Sum of Park \\
\hline Climate & $25.00 \%$ & $14.29 \%$ \\
Emissions & $25.00 \%$ & $14.29 \%$ \\
Energy & $25.00 \%$ & $42.86 \%$ \\
Ethics & $25.00 \%$ & $28.57 \%$ \\
\hline Grand Total & $\mathbf{1 0 0 . 0 0 \%}$ & $\mathbf{1 0 0 . 0 0 \%}$ \\
\hline
\end{tabular}

\section{Findings}

The following findings are organized by the three parent themes that were tracked and coded based on Elkington's TBL proposal (People, Planet, and Profit). These three parent nodes provided further opportunities to classify children, which helped answer the question of how TBL approaches differ among firms in an industry.

\subsection{People}

People encompasses all TBL initiatives that focus on the development of human capital, whether they are internal or external stakeholders in the firm.

$$
\begin{aligned}
& \begin{array}{c}
\text { communicating communicated donates } \\
\text { communications locals }
\end{array} \\
& \text { communicates diversion donation } \\
& \text { wellness community donated } \\
& { }_{\text {guarding }}^{\text {nation }} \text { national health training } \text { communicate }^{\text {nationaly }} \\
& \text { nations well local diversity donate } \\
& \begin{array}{l}
\text { communities' diverse } \\
\text { train } \\
\text { locally safe }
\end{array} \\
& \text { communicative communities healthful } \\
& \text { recreation }{ }_{\text {trained }} \text { communication trainings } \\
& \text { communities' passed }
\end{aligned}
$$

Figure 4. Word frequency analysis by top 100 child nodes for People parent node

By using the word cloud visualization tool, a crosstabulation was performed for various additional comparisons of how each firm differentiated their focus. Additionally, identifying these frequently occurring themes in the analysis divulged the most important themes as an aggregate in terms of the resources they devote to improving the lives of their 
people. A focus on the health and safety of their local communities lead the data. This discovery provides additional research opportunities in the form of case studies, interviews, or surveys regarding the impact of the company's resources spent on making sure their local communities are healthy and safe.

Table 5. Crosstab pivot table of top 3 People
child nodes by firm, sample
\begin{tabular}{|lrr|}
\hline Row Labels & .T Sum of Chatham & Sum of Diamondrock \\
\hline Health & $30.00 \%$ & $28.57 \%$ \\
Local & $40.00 \%$ & $42.86 \%$ \\
Safety & $30.00 \%$ & $28.57 \%$ \\
\hline Grand Total & $\mathbf{1 0 0 . 0 0 \%}$ & $\mathbf{1 0 0 . 0 0 \%}$ \\
\hline
\end{tabular}

From the table above, one can see that each organization has a slightly different focus when it comes to health, safety, and local responsiveness. This top-level analysis can help a firm identify where it needs to focus additional resources, or balance their current strategies to include other areas. For example, Park Hotels and Resorts emphasizes local impacts more than health and safety, identifying an opportunity to adjust their TBL strategy to address the health and safety of their stakeholders.

\subsection{Planet}

Figure 3 above depicts a word cloud of Planet child nodes. By analyzing the top three frequently occurring children (energy, waste, and water) another crosstabulation sample of the data for Planet child nodes shows the following.

\section{Table 6. Crosstab pivot table of top 3 Planet child nodes by firm, selection}

\begin{tabular}{|lrr|}
\hline Row Labels & $\boldsymbol{x}$ Sum of Chatham & Sum of Diamondrock \\
\hline Energy & $30.00 \%$ & $33.33 \%$ \\
Waste & $30.00 \%$ & $33.33 \%$ \\
Water & $40.00 \%$ & $33.33 \%$ \\
\hline Grand Total & $\mathbf{1 0 0 . 0 0 \%}$ & $\mathbf{1 0 0 . 0 0 \%}$ \\
\hline
\end{tabular}

The full data show four companies that focus equally on energy, water, and waste while others have a greater emphasis on one or two of the three. For example, Chatham emphasizes water more, while Diamondrock is equally split. This is a great example that helps answer how firms differ in their TBL approaches, and also provides groundwork for future research into each firms' response effectiveness by collecting and analyzing quantitative data from ESG reports for alignment with policies and resulting changes. If a firm is writing extensively about their energy initiatives, yet has no discernable improvement in their energy audit reports, an opportunity for both external agencies to intervene and internal innovation is presented.

This could also be as simple as notating what policies are being discussed by competitors, or potential clients, and comparing those issues to performance metrics, not as a means to differentiate a firm's product, but as a way to identify market needs possibly not being met in certain geographic areas. This would help alleviate the challenge of the echo-chamber nature of external reporting by adding another level of accountability, especially if topline qualitative data were compared to business-level insights from pulse surveys and quantitative expense data. For example, if a firm is externally reporting paperless initiatives as part of their strategy to reduce deforestation, yet paper supply expenses have not been significantly reduced in certain portfolio assets, there is an opportunity for attention and process improvements to align corporate goals with business-level operations.

\subsection{Profit}

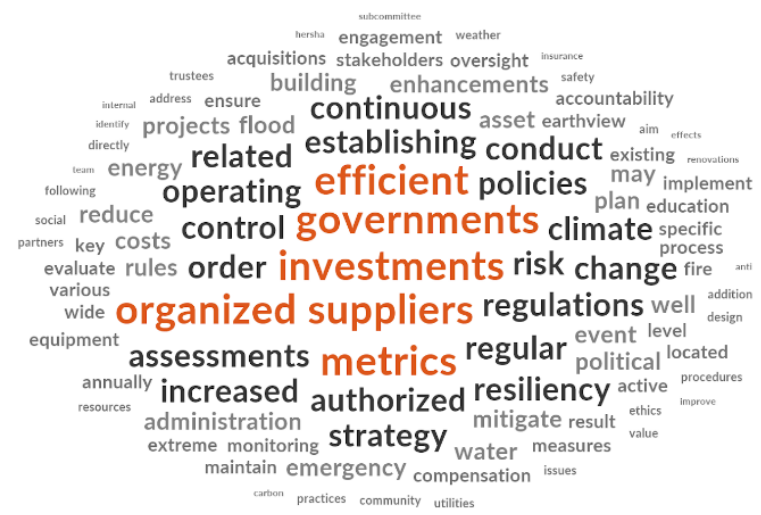

\section{Figure 5. Word frequency analysis by top 100} child nodes for Profit parent node

Figure 5 above depicts a word cloud of the Planet child nodes. Using the top three frequently occurring child nodes, another crosstabulation sample of the data for Planet shows the following. 
Table 7. Crosstab pivot table of top 3 Profit child nodes by firm, selection

\begin{tabular}{|lrr|}
\hline Row Labels & $\boldsymbol{T}$ Sum of Chatham & Sum of Diamondrock \\
\hline Government & $40.00 \%$ & $50.00 \%$ \\
Investment & $20.00 \%$ & $12.50 \%$ \\
Suppliers & $40.00 \%$ & $37.50 \%$ \\
\hline Grand Total & $\mathbf{1 0 0 . 0 0 \%}$ & $\mathbf{1 0 0 . 0 0 \%}$
\end{tabular}

Again, the analysis allows one to see where each company theoretically prioritizes the top three frequently occurring themes, and helps answer the question of how firms differ in their approach to TBL. For example, DiamondRock mentions very little about their investments in TBL, while Chatham has an equal ratio of government and supplier considerations. The full data table shows that investment is among the least-mentioned of the three themes, leaving room for improvement on how a firm can leverage investments and resources to drive TBL value creation.

\section{Discussion of findings}

This type of research could prove useful to firms, regulatory agencies, and complementor firms as internationalization proves to be one of the final efficiency frontiers, however it is important to get the processes right domestically before considering foreign shores. Unfortunately, Profit opportunities abroad can be very attractive to firms because of the nature of People and Planet regulations in emerging markets, but the right processes and best practices developed in a home country can protect People, Planet, and Profits in the long run when reaching abroad.

Regarding internal applications for this research, firms have access to large amounts of qualitative data in the form of candidate applications and interviews, exit data, annual reviews, notes and activity logs from Customer Relationship Management platforms, weekly reporting SOPs, top-level business intelligence dashboards, and from scraping social media and review websites. Firms can use a range of channels to capture additional insights in the form of surveys and online engagement to explore more opportunities for creating sustainable CSR initiatives that are meaningful in addressing real challenges that make themselves present in an analysis.

One immediately useful application in the People realm pertains to recruitment, as hoteliers navigate staffing challenges coming out of a global pandemic. Line-level hotel employees lack motivation to return to work at their previous pay, and with the added uncertainty of providing guest service with additional safety restrictions and pressures from supply chain volatility. A firm could potentially capture interview data, exit data, and onboarding data to review how to better serve their people and retain talent to both gain competitive advantage and create a more healthy work environment.

Regulatory agencies can use this type of analysis to formulate where to allocate oversight, funding, and infrastructure resources, as well as where to deploy educational and counseling resources for firms that are struggling to engage with some of their areas of inefficiencies.

Lastly, there is also an opportunity to encourage B2B relationships and to create truly shared value by allowing complementor firms to access or integrate their data and resources to identify areas of need within an industry. One example of this is Global Distribution Systems (GDS) that connect hotels, airlines, car rentals, and travel agencies to one another through a computerized network that holds a virtually infinite amount of data. With GDS consolidated to just a few firms (Amadeus, Galileo, Sabre, and Worldspan), it may even be critical for GDS to use this type of qualitative data analysis, not only to identify opportunities to offer expert services to individual firms within the larger travel and leisure industry, but also to take more ownership of their own CSR initiatives to create meaningful change. Many individual firms are often beholden to rules and regulations from each GDS. Creating shared value will not truly work unless each firm along the value chain is aware of, and responsible for, better business. GDS have already implemented programs due to safety concerns from travelers, and businesses, in light of Covid-19, so it is not outside of the realm of feasibility if enough attention and funding were allocated to new frontiers in a proactive sense, instead of a response to an eminent economic impact.

In regard to globalization, there are differences in what shared value even means for emerging economies compared to developed countries, and a proactive qualitative data analysis can be used to avoid mistakes that were made domestically in an effort to preserve cultural resources in target locations. Qualitative data analysis like this can be used to develop customized solutions to international expansion, or even avoid it at all if the endeavor does not meet the needs of both internal and external stakeholders.

\section{Conclusion}

One challenge presented from this document analysis is that if something similar were performed internally on a firm's own publicly-facing documents, 
the output may result in essentially just an outline of what the author used to write their document with. This is why it makes more sense to use organic data from within the firm to identify themes that are important to stakeholders in the form of surveys, guest feedback, interviews, and employee pulse data.

However, this research presents a unique opportunity for regulatory agencies and complementor firms to evaluate areas for intervention. For instance, one of the first analyses was performed to compare the document quantities and types contributed by each firm. Hersha did not contribute any policies to the document collection, so when reflecting on what that revealed about the type of data collected, a question arose about why some firms would opt to share their policies publicly if they are not legally required to do so. Is this an indication of a commitment to transparency or a response to a previous incident? Without an in-depth interview or survey conducted within each firm's corporate governance, it would be impossible to understand the implications or justifications for why certain documents are shared with the public. On the other hand, an analysis like this might give regulatory agencies some insights into what kinds of documents might be important to mandate as publicly available information, or set more standards for what and how information is shared with the public regarding TBL.

Another important consideration for this research takes into account the individual voices and writing styles used in the documentation. At what point do conferences, lectures, and research reinforce important topics that permeate the data that are collected? Can the words being used truly reflect the reality of a firm's TBL environment, or is quantitative data the only way to measure the effectiveness?

Not only do the individual authors' voices contribute to the quality of data presented here and to the public, but differences in geographic regions, regulations, and corporate governance drive the narratives being written about how the firm is addressing and performing in terms of TBL. But addressing and evaluating performance is rather ouroboros in nature if firms are not looking to organic data within their organization and among their stakeholders for their respective north star.

Strategic management theory leaves much to be answered for business people who care about improving the world for future generations. The frameworks that have been developed for the masses focus on dollars, but do not make much sense when industrialized economies have a growing gap in wealth and prosperity for the average worker compared to their CEO. Why would workers in emerging economies want the same dynamic unless they stood to truly gain from the exchange? While the current efficiency frontier is leading firms to internationalize, globalization should be the penultimate frontier, with the final efficiency frontier being every human on the planet having their basic needs met. Qualitative data are the perfect place to start for identifying and measuring the aspects of what meets the needs of the planet's people. This supports Elkington's recall of TBL as he originally defined it, because the point of CSR is not to meet requirements, it is to innovate ways to exceed society's expectations and increase efficiencies in an effort to make sure decision-makers are making decisions that serve both the firm's ability to remain profitable while also giving a voice to every stakeholder.

Additionally, as emerging economies begin to navigate industrialization and expansion on capitalist ideologies, CSR as it stands presently does not do much to address the inequities of capitalism. Capitalism is responsible for our societal advancements, however, with that responsibility comes accountability for making sure the tools are accessible and innovated to further benefit society, since society is what supports capitalism.

Some constraints in this research make it complicated to commit to a truly cogent conclusion, but this feels like the start of something that could take several years, and maybe even a lifetime, to fully explore and understand. The basis of this gateway data collection and analysis has important implications when looking at how firm performance is evaluated moving forward into this era of Big Data. Data lakes of text, photos, videos, sound, websites, charts, and tables are waiting to be used in meaningful ways, and by taking a qualitative analysis approach to the data to monitor and evaluate firm performance in the TBL realm, maybe Elkington's new vision of an accountability aspect of TBL can be realized.

\section{References}

[1] Rahul, Rajalakshmi. (2012). Theories of CSR. Knowledge Tank; Project Guru. Retrieved from projectguru.in/theories-of-csr/ [2] Stakeholder Theory. (2018) About. Retrieved from stakeholdertheory.org/about/

[3] Guzman, C.G. (2016). Deontology Vs Utilitarianism, The Eternal Battle. Retrieved from

sites.psu.edu/psy533buban/2016/02/05/103-deontology-vs-uti litarianism-the-eternal-battle/ 
[4] Altman, Matthew C. (2007). The Decomposition of the Corporate Body: What Kant Cannot Contribute to Business Ethics. Journal of Business Ethics, 74(3), 253-266.

[5] Mahto,Monika; Hogan, Susan K.; Hatfield, Steve; Dr. Coppola, Michela; Kulkarni, Abha. (2020). Looping in your new sidekick. Retrieved from

deloitte.com/us/en/insights/focus/technology-and-the-futureof-work/machine-learning-qualitative-data.html

[6] Xie, Zongjie; Hall, Jeremy; McCarthy, Ian P.; Skitmore, Martin; Shen, Liyin. (2016). Standardization efforts: The relationship between knowledge dimensions, search processes and innovation outcomes. Technovation, 48-49, 69-78.

[7] Friedman, Milton. (1970). The Social Responsibility of Business is to Increase its Profits. The New York Times Magazine, SM, 17.

[8] Bower, Joseph L. and Paine, Lynn S. (2017). The Error at the Heart of Corporate Leadership. Retrieved from hbr.org/2017/05/the-error-at-the-heart-of-corporate-leadershi $\mathrm{p}$

[9] Hounshell, David A. (1988). The Same Old Principles in New Manufacturing. Retrieved from

hbr.org/1988/11/the-same-old-principles-in-the-new-manufac turing

[10] Taylor, Frederick Winslow. The Principles of Scientific Management. New York: Harper \& Brothers, 1911.

[11] Kraaijenbrink, Jeroen. (2019). What The 3Ps Of The Triple Bottom Line Really Mean. Retrieved from forbes.com/sites/jeroenkraaijenbrink/2019/12/10/what-the-3p s-of-the-triple-bottom-line-really-mean

[12] Bowen, Howard R. Social Responsibilities of the

Businessman. New York: Harper, 1953.

[13] Porter, Michael. (2011). Creating Shared Value.

Retrieved from

hbr.org/2011/01/the-big-idea-creating-shared-value

[14] Elkington, John. (2018). 25 Years Ago I Coined the

Phrase 'Triple Bottom Line.' Here's Why It's Time to

Rethink It. Retrieved from

hbr.org/2018/06/25-years-ago-i-coined-the-phrase-triple-bott om-line-heres-why-im-giving-up-on-it

[15] International Monetary Fund. (2021). World Economic Outlook Database. Retrieved from

statista.com/statistics/269959/employment-in-the-united-state $\mathrm{s}$

[16] International Monetary Fund. (2021). World Economic Outlook Database. Retrieved from

statista.com/statistics/1214226/number-of-hotel-jobs-us

[17] AHLA. (2021). Retrieved from www.ahla.com/faq

[18] STR. (2020). Retrieved from

str.com/press-release/us-hotel-industry-posts-record-levels-20

19-lowest-growth-recession

[19] CSRHub. (2021). Consensus ESG Ratings. Retrieved

from esg.csrhub.com/esg
[33] Designing Custom Encoders. (2008) Oracle, Santa

Clara, CA, USA. Part No: 820-3742. Accessed on September 10, 2021. Retrieved from

docs.oracle.com/cd/E19509-01/820-3742/index.html

\subsection{Data Sources}

All data sources taken directly from publicly available information at each company's website(s).

\section{Chatham Lodging Trust}

[20] chathamlodgingtrust.com/responsibility/

CorePoint Lodging

[21] corepoint.com/responsibility

\section{DiamondRock Hospitality}

[22]investor.drhc.com/news-releases/news-release-details/dia mondrock-hospitality-company-recognized-global-sector-lea der

[23] investor.drhc.com/sustainability-report

Hersha Hospitality Trust

[24] hersha.com/earthview

MGM Properties

[25]mgmgrowthproperties.com/about-us/Environment-and-S ocial/default.aspx

[26]mgmresorts.com/en/company/csr/fostering-relationships. html

[27] mgmresorts.com/en/company/csr.html

\section{Park Hotels \& Resorts}

[28] pkhotelsandresorts.com/responsibility

Pebblebrook Hotels

[29] pebblebrookhotels.com/corporate-responsibility

Ryman Hospitality Properties

[30] ir.rymanhp.com/index.php/sustainability

Summit Hotel Properties

[31] shpreit.com/responsibility/about/

Sunstone Hotel Investors, Inc

[32] sunstonehotelinvestorsinc.gcs-web.com/sustainability

\subsection{Software}

All data queries were processed in Nvivo Qualitative Data Analysis Software.

QSR International. (1999). NVivo Qualitative Data Analysis Software. Available from

qsrinternational.com/nvivo/nvivo-products/

All tables and figures created by the author based on analysis performed in Nvivo and manipulated in Excel.

Microsoft Corporation. (2018). Microsoft Excel. Available from office.microsoft.com/excel 